\title{
Large-area, Highly Uniform Evaporated Formamidinium Lead Triiodide Thin-films for Solar Cells
}

\author{
Juliane Borchert, Rebecca L. Milot, Jay B. Patel, Christopher L. Davies, Adam \\ D. Wright, Laura Martínez Maestro, Henry J. Snaith, Laura M. Herz, and \\ Michael B. Johnston* \\ Clarendon Laboratory, Department of Physics, University of Oxford, Parks Road, \\ OX1 3PU, United Kingdom \\ E-mail: michael.johnston@physics.ox.ac.uk
}

\begin{abstract}
Perovskite thin-film solar cells are one of the most promising emerging renewable energy technologies because of their potential for low-cost, large-area fabrication combined with high energy conversion efficiencies. Recently, formamidinium lead triiodide $\left(\mathrm{FAPbI}_{3}\right)$ and other formamidinium $\left(\mathrm{CH}\left(\mathrm{NH}_{2}\right)_{2}\right)$ based perovskites have been explored as interesting alternatives to methylammonium lead triiodide $\left(\mathrm{MAPbI}_{3}\right)$, because they exhibit better thermal stability. However at present a major challenge is up-scaling of perovskite solar cells from small test-cells to full solar modules. We show that coevaporation is a scalable method for the deposition of homogeneous $\mathrm{FAPbI}_{3}$ thin-films over large areas. The method allows precise control over film thickness and results in highly uniform, pin-hole free layers. Our films exhibited a high charge-carrier mobility of $26 \mathrm{~cm}^{2} \mathrm{~V}^{-1} \mathrm{~s}^{-1}$, excellent optical properties and a bimolecular recombination constant
\end{abstract}


of $7 \times 10^{-11} \mathrm{~cm}^{3} \mathrm{~s}^{-1}$. Solar cells fabricated using these vapor-deposited layers within a regular device architecture produced stabilized power conversion efficiencies of up to $14.2 \%$. Thus we demonstrate that efficient $\mathrm{FAPbI}_{3}$ solar cells can be vapor-deposited, which opens up a pathway towards large-area stable perovskite photovoltaics.
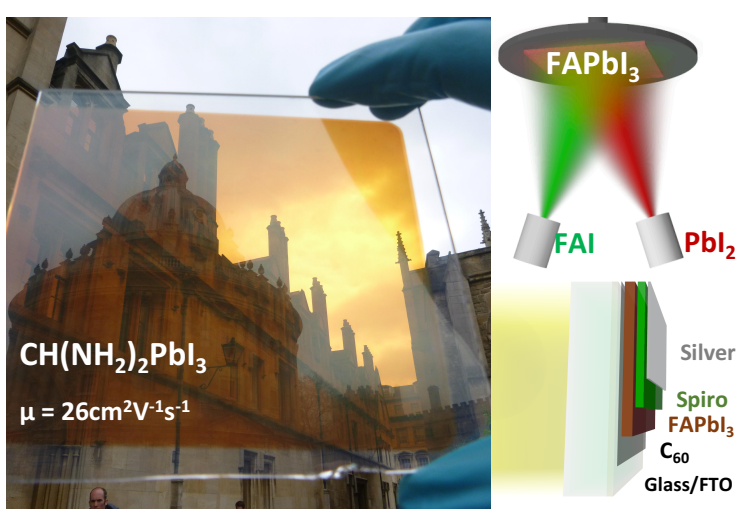
Hybrid organic-inorganic perovskite halide solar cells have attracted much attention in recent years because of their remarkably fast rise in power conversion efficiencies (PCE). ${ }^{1}$ While PCEs above $20 \%$ have been achieved by multiple research groups ${ }^{2-4}$ the stability and up-scalability of perovskite solar cells remain obstacles to their commercialization. Methylammonium lead triiodide $\left(\mathrm{CH}_{3} \mathrm{NH}_{3} \mathrm{PbI}_{3}=\mathrm{MAPbI}_{3}\right)$ has been the most commonly used and investigated perovskite solar cell material. However more recently formamidinium lead triiodide $\left(\mathrm{CH}\left(\mathrm{NH}_{2}\right)_{2} \mathrm{PbI}_{3}=\mathrm{FAPbI}_{3}\right)$ and other perovskites containing formamidinium have been studied as they offer a number of advantages over $\mathrm{MAPbI}_{3}$. Specifically, $\mathrm{FAPbI}_{3}$ has a narrower band gap of $1.47 \mathrm{eV}$ which results in an extension of the absorption into the near infrared, ${ }^{5}$ and $\mathrm{FAPbI}_{3}$ also exhibits better thermal stability than $\mathrm{MAPbI}_{3} .{ }^{6}$ Mixed-cation perovskites combining formamidinium and other cations such as methylammonium or cesium have been shown to be even more thermally stable, ${ }^{7,8}$ while using both mixed cations and mixed halides enables stable perovskite thin films to be created with a widely tunable band gap. ${ }^{9}$

$\mathrm{FAPbI}_{3}$ thin-films have been fabricated using a variety of methods, with spin-coating from solution being the most common. ${ }^{6,10}$ Others have used pre-deposited $\mathrm{PbI}_{2}$ films which they converted into $\mathrm{FAPbI}_{3}$ by dipping in solutions containing $\mathrm{FAI},{ }^{5}$ and it has also been demonstrated that $\mathrm{FAPbI}_{3}$ thin-films can be grown in a chemical vapor deposition (CVD) furnace. ${ }^{11}$

Vacuum based deposition processes such as co-evaporation are advantageous because they result in highly uniform, pin-hole free, smooth thin films. ${ }^{12}$ Pin-hole free films are particularly important for large-area solar cells in order to avoid short circuits between electron and hole transport layers that limit PCEs and fill factors. Good thickness uniformity and low roughness is important for reliable solar cell production and also facilitates advanced optoelectronic characterization of the material. ${ }^{12}$ Using co-evaporation and highly optimized contact layers efficiencies of up to $20 \%$ have been reached for $\mathrm{MAPbI}_{3}$ based solar cells. ${ }^{3}$ Additionally, vacuum based deposition does not require solvents, so is a ideal method for 
depositing perovskite thin films in multi-layer stacks and on sensitive substrates. This is particularly useful for the fabrication of tandem solar cells ${ }^{8,13}$ and solar cells on flexible substrates.

In this study, we combine the advantages of formamidinium based perovskites with the advantages of thermal evaporation under vacuum. We used co-evaporation to deposit large area $(8 \mathrm{~cm} \times 8 \mathrm{~cm})$, highly uniform $\mathrm{FAPbI}_{3}$ thin-films that possessed excellent material properties. The films exhibited a high charge carrier mobility of $26 \mathrm{~cm}^{2} \mathrm{~V}^{-1} \mathrm{~s}^{-1}$ and a very low surface roughness with a root mean square $\left(\mathrm{R}_{\mathrm{RMS}}\right)$ of only $6.2 \mathrm{~nm}$. We also fabricated efficient solar cell devices based on co-evaporated $\mathrm{FAPbI}_{3}$ which produced $\mathrm{PCEs}$ of up to $15.8 \%$, with a stabilised power output (SPO) efficiency of $14.2 \%$.

Solar cells were fabricated using a simple planar architecture on fluoride-doped tin oxide (FTO) coated glass substrates. Briefly, they consisted of an evaporated $\mathrm{C}_{60}$ layer as the electron transport layer, ${ }^{14}$ a $300 \mathrm{~nm}$ thick absorber layer of co-evaporated $\mathrm{FAPbI}_{3}$ and a spin-coated hole transport layer of 2,2',7,7'-Tetrakis-( $N, N$-di-4-methoxyphenylamino)-9,9'spirobifluorene (Spiro-OMeTAD). Finally, multiple $100 \mathrm{~nm}$ thick silver electrodes with an area of $9.19 \mathrm{~mm}^{2}$ were evaporated, these electrodes defined the pixel size of the test solar cell devices. Full details of device fabrication are provided in the Supporting Information. The device performance was assessed using current density-voltage $(\mathrm{J}-\mathrm{V})$ sweeps and photocurrent spectroscopy under simulated sunlight. As shown in Figure 1a the power conversion efficiency (PCE) of our champion cell was $15.8 \%$ with an open circuit voltage ( $\mathrm{V}_{\mathrm{OC}}$ ) of $1.01 \mathrm{~V}$ and a short circuit current $\left(\mathrm{J}_{\mathrm{SC}}\right)$ of $22.1 \mathrm{mAcm}^{-2}$. To test the stabilisation of the solar cell performance under working conditions, the same cell was held close to the maximum power point for $50 \mathrm{~s}$. The PCE stabilized at $14.2 \%$ (Figure 1b) and the current stabilized at $17 \mathrm{mAcm}^{-2}$.

Figure 1c shows the external quantum efficiency (EQE) spectrum of the champion device measured in short circuit under 1 sun $\left(1 \mathrm{~kW} / \mathrm{cm}^{2}\right.$ AM1.5) illumination. The EQE peaks at $80 \%$ and shows high values over the wavelength range $400 \mathrm{~nm}-600 \mathrm{~nm}$. However a drop 
in EQE to values $\sim 60 \%$ is observed for wavelengths between $600 \mathrm{~nm}$ and the $\mathrm{FAPbI}_{3}$ bandedge. We attribute this feature to optical interference in the planar device-stack, coupled with a lower absorption coefficient of the perovskite layer at longer wavelengths. We therefore anticipate that producing devices with a thicker $\mathrm{FAPbI}_{3}$ layer, and utilizing optical modelling to optimize the thicknesses of all layers in the device stack would further improve the PCE of these cells.

The integrated current over the spectrum is $19 \mathrm{mAcm}^{-2}$ which is close to the $\mathrm{J}_{\mathrm{SC}}$ recorded in the $\mathrm{J}-\mathrm{V}$ measurements: $22 \mathrm{mAcm}^{-2}$ for both the forward and reverse scan, and $17 \mathrm{mAcm}^{-2}$ stabilized. Additional cell performance data can be found in the Supporting Information. Overall, we were able to fabricate solar cells with a high PCE which also stabilized at similarly high efficiencies. This result shows that vapor depositing $\mathrm{FAPbI}_{3}$ yields efficient solar cells in a relatively simple, planar cell architecture. 

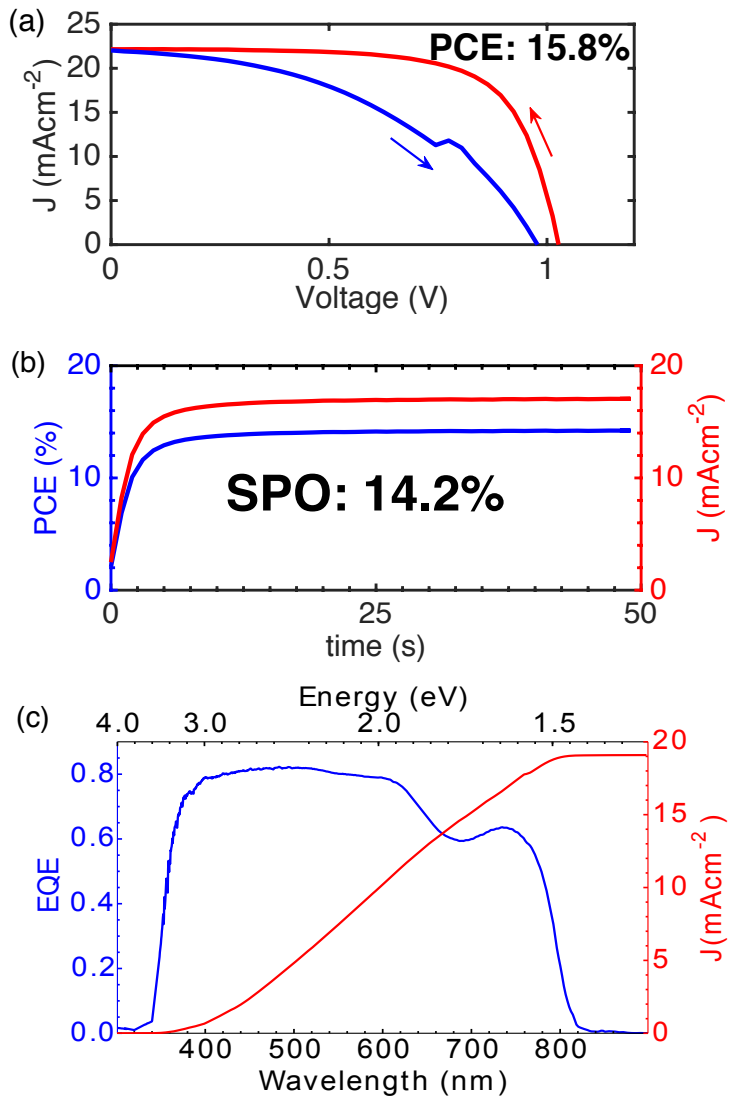

Figure 1: (a) Current-voltage ( $\mathrm{J}-\mathrm{V}$ ) curve of the champion evaporated $\mathrm{FAPbI}_{3}$ device. The short circuit current density $\left(\mathrm{J}_{\mathrm{SC}}\right)$ was $22.1 \mathrm{mAcm}^{-2}$, the open circuit voltage $\left(\mathrm{V}_{\mathrm{OC}}\right)$ was $1.01 \mathrm{~V}$ and the power conversion efficiency (PCE) was $15.8 \%$. Significant hysteresis can be observed between the forward (blue) and reverse (red) sweeps. (b) The stabilized power output measurement (SPO), showing a stabilised efficiency of $14.2 \%$ (blue) and a stabilised current of $17 \mathrm{mAcm}^{-2}$ (red). (c) The external quantum efficiency (EQE) spectrum (blue) of the same device with the integrated current over the EQE spectrum (red) being $19 \mathrm{mAcm}^{-2}$. 


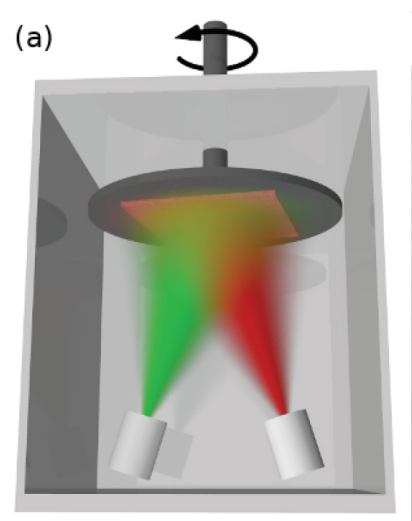

(d)

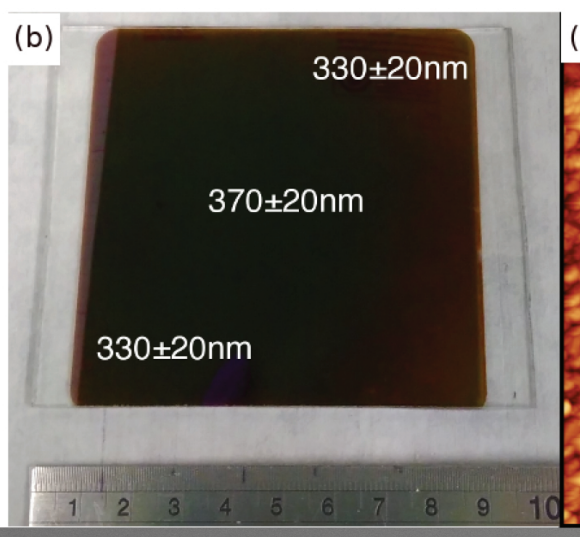
FT

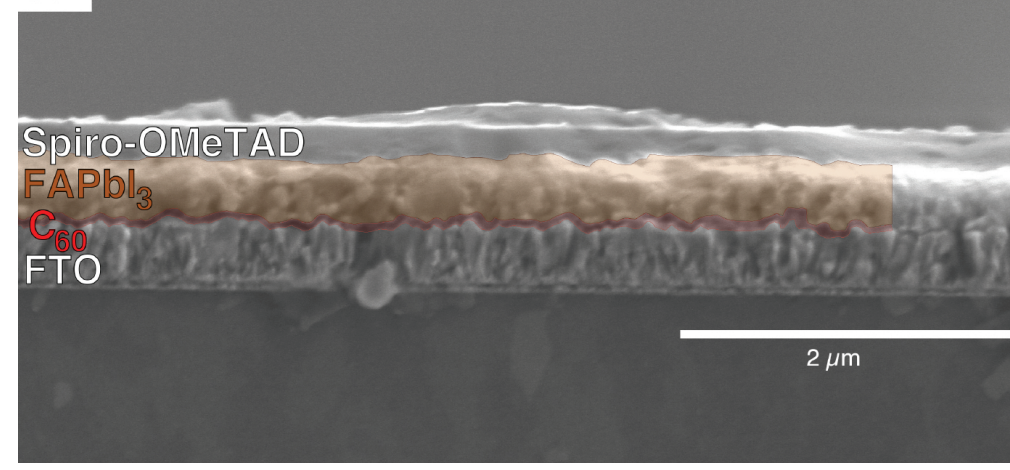

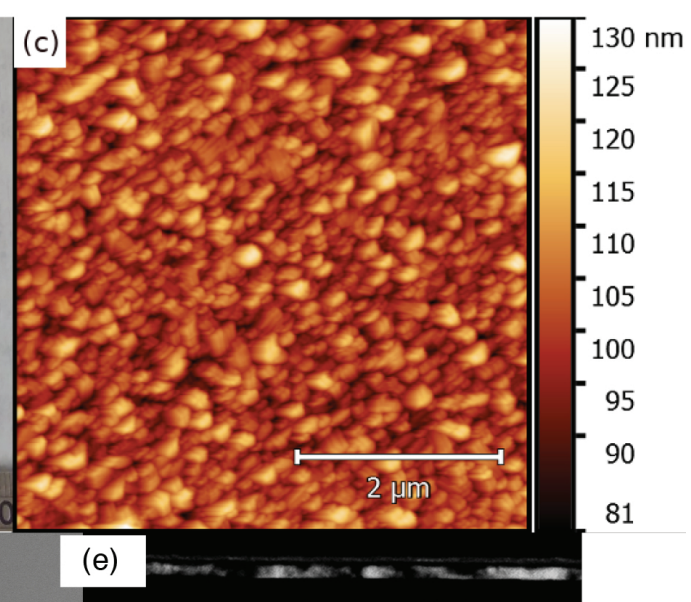

Spiro-OMeTAD

Figure 2: (a) Schematic diagram of the dual-source co-evaporation system used in this study. (b) Photograph of a $8 \mathrm{~cm} \times 8 \mathrm{~cm}$ thin film of $\mathrm{FAPbI}_{3}$ deposited on a glass substrate. The image shows the substrate after thermal annealing at $170^{\circ} \mathrm{C}$ for 1 minute. The results of thickness measurements at 3 positions are superimposed on the image, and a metal ruler with a centimeter scale is shown as a size reference. (c) Atomic force micrograph of a $5 \mu \mathrm{m} \times 5 \mu \mathrm{m}$ region of the sample. The surface was found to be very smooth with a root mean square roughness $R_{\mathrm{RMS}}=6.2 \mathrm{~nm}$. (d) A scanning electron microscopy image and (e) a scanning transmission electron microscopy image of a full $\mathrm{FAPbI}_{3}$ solar cell. From the bottom the layers are: a glass substrate, fluorine doped tin oxide (FTO) layer, thin $\mathrm{C}_{60}$ layer, $\mathrm{FAPbI}_{3}$ layer a spiro-OMeTAD layer and the silver electrode.

To assess the uniformity of the co-evaporation method, we deposited a large-area $\left(64 \mathrm{~cm}^{2}\right)$ $\mathrm{FAPbI}_{3}$ film directly onto a glass sheet. Our evaporation system had a relatively short working distance of $20 \mathrm{~cm}$ between the thermal sources and the rotating substrate (schematically shown in Figure 2a). Therefore it is expected that any evaporated film should be thickest the centre of the substrate, with thickness reducing as a function of radius. A photograph of the deposited film after annealing is shown in Figure 2b. We measured the thickness of the $\mathrm{FAPbI}_{3}$ layer in three areas on this film using a profilometer. In each area at least 
seven measurements were performed to calculate a mean thickness value (see Figure SI 1 for further details). The film had a thickness of $370 \pm 20 \mathrm{~nm}$ at the centre of the substrate, and as expected, the thickness dropped as a function of radius to $330 \pm 20 \mathrm{~nm}$ in the corners of the substrate. A straightforward approach to further improving the uniformity of the films is to use a deposition system with a large working distance.

We performed atomic force microscopy (AFM) measurements to determine the surface roughness and surface coverage of the film. Figure 2c is an AFM image recorded over an area of $5 \mu \mathrm{m} \times 5 \mu \mathrm{m}$. The film is very smooth with a surface roughness of only $R_{\mathrm{RMS}}=6.2 \mathrm{~nm}$ over the image area. This value is much lower than the surface roughness of $\mathrm{FAPbI}_{3}$ thin films produced by other methods, with reported roughness values ranging from $18 \mathrm{~nm}^{15}$ to above $100 \mathrm{~nm} .{ }^{16}$ We also found that the film was very homogeneous and had no pinholes. We conclude that evaporation leads to significantly smoother and more homogeneous films from which we would expect very little light scattering. Indeed this is confirmed by the visible absorption and transmission and reflection spectra shown in Figure 3a where there is very little scatter below the onset of absorption. The absorption onset is around $1.5 \mathrm{eV}$ which is consistent with the previously reported values for the absorption onset in solution processed $\mathrm{FAPbI}_{3}$. Together, the profilometer, AFM and absorption measurements show that we fabricated very uniform and smooth $\mathrm{FAPbI}_{3}$ thin-films.

To clarify the crystal phases present in the thin film we performed X-ray diffraction measurements. At room temperature, $\mathrm{FAPbI}_{3}$ can be either in a black, trigonal, perovskite phase or in a yellow, hexagonal, non-perovskite phase. ${ }^{17,18}$ Only thin films in the black phase are suitable for use as absorbers in solar cells so it is necessary to ensure that the film is in the right phase. The diffraction patterns are shown in Figure $3 c$ and confirms that after 1 minute of annealing at $170^{\circ} \mathrm{C}$ the material was in the black perovskite $\alpha-\mathrm{FAPbI}_{3}$ phase. In the annealed sample, all X-ray reflections are consistent with this $\alpha$ structure, however in the as-deposited (unannealed) sample, the intensity of the perovskite reflection is strongly reduced, and the most intense peaks are consistent with the yellow, non-perovskite $\delta$ phase 
of $\mathrm{FAPbI}_{3} \cdot{ }^{17}$ This confirms that in the as-deposited film the yellow $\delta-\mathrm{FAPbI}_{3}$ is dominant and upon annealing it is converted to the black $\alpha-\mathrm{FAPbI}_{3}$ phase. In evaporated $\mathrm{MAPbI}_{3}$ thin films, annealing is not necessary to obtain high solar cell efficiencies ${ }^{19}$ because there are no competing non-perovskite $\mathrm{MAPbI}_{3}$ phases. In contrast, for $\mathrm{FAPbI}_{3}$ annealing is essential in order to obtain the perovskite phase. Overall, we observed the same phase behaviour as has been reported for solution processed $\mathrm{FAPbI}_{3}{ }^{18}$ and single crystals. ${ }^{17}$ Interestingly for evaporated $\mathrm{FAPbI}_{3}$ thin-films only a very short annealing is necessary to obtain the desired $\alpha$-phase. It is well known that the $\alpha-\mathrm{FAPbI}_{3}$ phase is not long-term stable and converts to a yellow hexagonal phase when exposed to humidity (see Figure S5). To address this problem co-evaporation of cesium, methylammonium or bromide could be used to stabilize the perovskite phase.

To learn more about the morphology of the films and the crystal quality, we performed scanning electron microscopy (SEM) and scanning transmission electron microscopy (STEM) on full solar cell devices. A typical cross-sectional SEM image of a device is shown in Figure $2 \mathrm{~d}$ where a smooth, uniform film of $\mathrm{FAPbI}_{3}$ (colored brown in the image) can be seen. In our survey of cross-sections we did not observe any evidence of pinholes in the $\mathrm{FAPbI}_{3}$ layer. To observe the crystal quality and interfaces, high-resolution STEM images were taken on thin cross-sectional lamella of the device. The lamella were prepared using a focused ion beam (FIB), as described in the Supporting Information. The STEM image in Figure 2e shows crystallites of different orientations within the perovskite film, with some extending vertically through the film. The STEM image also shows high contrast between the $\mathrm{FAPbI}_{3}$ (bright) and the carbon rich (dark) $\mathrm{C}_{60}$ and Spiro-OMeTAD that surround it. Close inspection of Figure 2e reveals regions of direct contact between the $\mathrm{FAPbI}_{3}$ and FTO layers which has been shown previously to lead to hysteretic J-V curves similar to that shown in Figure 1a. ${ }^{19}$ 

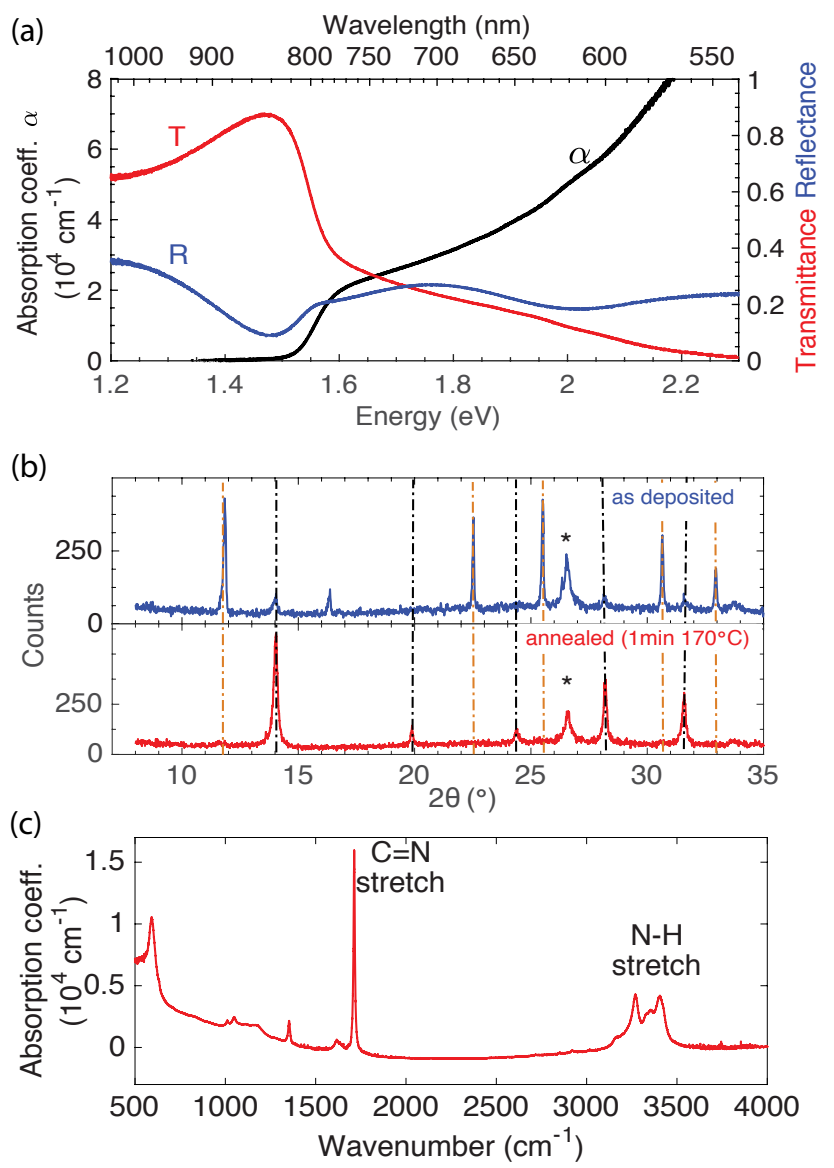

Figure 3: (a) The absorption (black line) of the co-evaporated $\mathrm{FAPbI}_{3}$ thin-films in the visible is calculated from the transmission (red line) and reflection (blue line) spectra. As expected an absorption onset around $1.5 \mathrm{eV}$ is observed. (b) The infrared absorption spectrum of the film showing the characteristic absorption peaks for $\mathrm{FAPbI}_{3}$. (c) The X-ray diffraction pattern for an as-deposited and for an annealed film. The orange lines mark the expected position corresponding to the yellow non-perovskite $\delta-\mathrm{FAPbI}_{3}$ phase, whereas the black dashed lines mark the peaks matching the perovskite $\alpha-\mathrm{FAPbI}_{3}$ phase. ${ }^{17}$ The star marks the FTO substrate peak. 

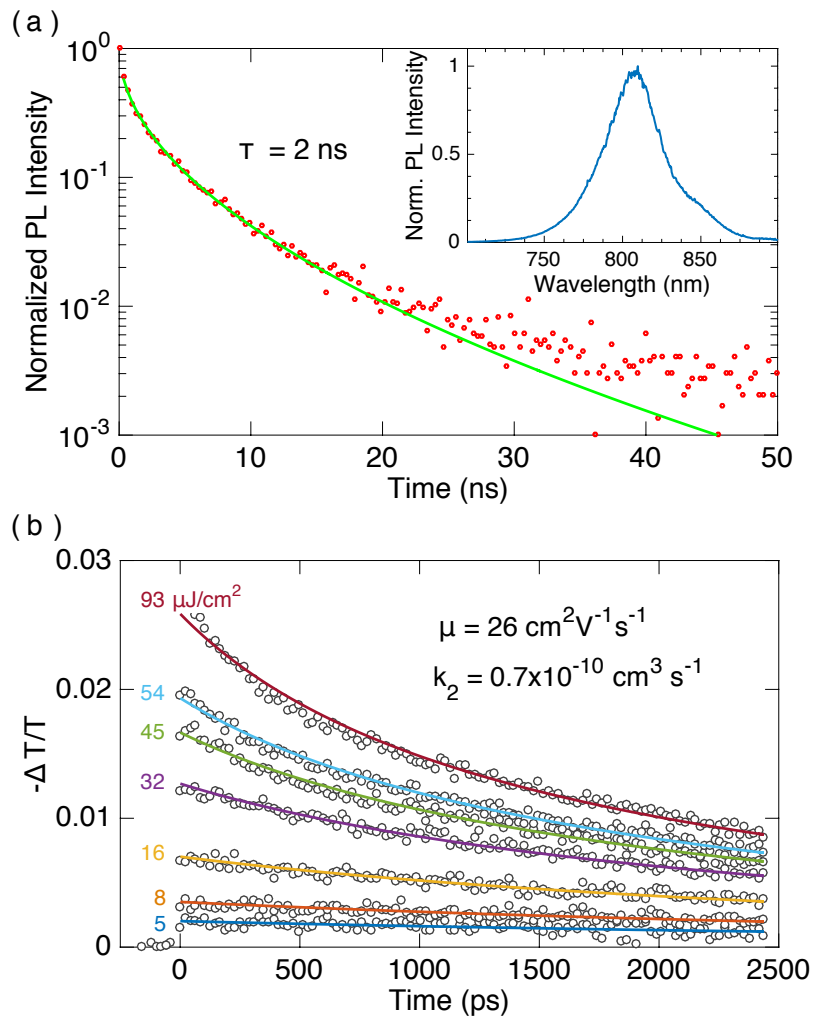

Figure 4: (a) Photoluminescence (PL) from an evaporated $\mathrm{FAPbI}_{3}$ thin film. The PL decay is fit using a stretched exponential function to extract an average monomolecular chargecarrier lifetime of $2 \mathrm{~ns}$. The PL spectrum shown in the inset has a peak at $805 \mathrm{~nm}(1.54 \mathrm{eV})$. (b) Optical pump / THz probe measurements of the charge-carrier recombination dynamics in the evaporated $\mathrm{FAPbI}_{3}$ thin film on z-cut quartz. The sample was photoexcited at $400 \mathrm{~nm}$ with various fluences ranging from $5-93 \mu \mathrm{J} / \mathrm{cm}^{2}$ as labeled on the graph. The open circles represent experimental data points, and the solid lines are fits to Equation 1 of the Supporting Information.

The photoluminescence (PL) spectrum of co-evaporated and annealed $\mathrm{FAPbI}_{3}$ film is shown in the inset of Figure 4a. The PL peak is at a wavelength of approximately $805 \mathrm{~nm}$ $(1.54 \mathrm{eV})$ in agreement with previous reports for solution-processed $\mathrm{FAPbI}_{3} \cdot{ }^{6,17,20}$ The full width at half-maximum of the PL spectrum for the vapor-deposited sample was $79 \mathrm{meV}$, which is slightly narrower than that previously reported for a solution-processed sample $(88 \mathrm{meV}) .{ }^{20}$ Since PL broadening is a combination of both homogeneous broadening and disorder broadening, ${ }^{21}$ the narrower PL emission observed from the evaporated films may be 
an indication of reduced disorder, however an in-depth study of PL as a function of excitation fluence and temperature would be required to confirm this. Figure 4a shows the measured time-resolved PL transient fitted with a stretched exponential function in order to account for a superposition of exponential decays. ${ }^{19,22}$ The average monomolecular lifetime $\tau$ of these decays is $2 \mathrm{~ns}$, which is significantly lower than that typically reported for solution processed $\mathrm{FAPbI}_{3}$ films. ${ }^{6,23,24}$ Our measured lifetimes are similar to previously reported lifetimes for vapor deposited $\mathrm{MAPbI}_{3}$ films. ${ }^{25}$ Optimisation of deposition parameters to increase the $\mathrm{PL}$ lifetime offers another opportunity of improving the efficiency of solar cells based on these films, which show remarkably high PCEs given the very short PL lifetimes.

$\mathrm{THz}$ photoconductivity measurements were performed to assess the charge mobility and recombination dynamics in co-evaporated $\mathrm{FAPbI}_{3}$. Figure $4 \mathrm{~b}$ shows the change in photoconductivity for a thin film of co-evaporated $\mathrm{FAPbI}_{3}$ as a function of time after photo-excitation with 35 fs laser pulses. From these data the charge carrier mobility was found to be $26 \mathrm{~cm}^{2} \mathrm{~V}^{-1} \mathrm{~s}^{-1}$ and an apparent ${ }^{26}$ bimolecular recombination rate constant of $k_{2}^{\text {apparent }}=0.7 \times 10^{-10} \mathrm{~cm}^{3} \mathrm{~s}^{-1}$ was extracted. Both parameters are nearly identical to the values determined for solution-processed $\mathrm{FAPbI}_{3}$ films. ${ }^{24,27}$ Using the measured carrier lifetime and mobility we extract a charge carrier diffusion length ${ }^{24}$ of $360 \mathrm{~nm}$ for a charge-carrier density typical for this material under solar illumination $\left(10^{15} \mathrm{~cm}^{-3}\right) \cdot{ }^{27}$ This is longer than the thickness of our absorber layer and therefore sufficiently long to allow the charges to migrate to the interfaces with the charge transport layers. These $\mathrm{THz}$ measurements show that the evaporated $\mathrm{FAPbI}_{3}$ possesses good charge conduction properties, comparable with the perovskite materials used in high efficiency solar cells.

We were able to co-evaporate formamidinium iodide and lead iodide to deposit $\mathrm{FAPbI}_{3}$ thin films. The deposited films were smooth and uniform over a large area of roughly 8 by $8 \mathrm{~cm}$ which demonstrates the advantages of vapor deposition for large-area perovskite solar cells. The film properties were similar to previously reported properties of $\mathrm{FAPbI}_{3}$. 
We fabricated solar cells from these thin films and achieved a stabilized power conversion efficiency of $14.2 \%$. This is a highly promising result which with further improvements in interface engineering can lead to even higher efficiencies. Being able to vapor deposit $\mathrm{FAPbI}_{3}$ is a key step towards the up-scaling of perovskite solar cells. ${ }^{28}$ It opens up the possibility of fabricating the more stable, multi-cation perovskites such as $\mathrm{FA}_{\mathrm{y}} \mathrm{Cs}_{\mathrm{y}-1} \mathrm{~Pb}\left(\mathrm{I}_{1-\mathrm{x}} \mathrm{Br}_{\mathrm{x}}\right)_{3} \mathrm{using}$ the highly scalable co-evaporation route. Thus our results are an important milestone on the way to large-area, stable thin-film perovskite solar cells.

\section{Acknowledgement}

The authors gratefully acknowledge the financial support from the Engineering and Physical Sciences Research Council (UK) (EPSRC). J.B.P. thanks the EPSRC and Merck Chemicals for the financial support through an Industrial CASE studentship. J.B. thanks the EPSRC for funding via the Centre for Doctoral Training in New and Sustainable Photovoltaics. A.D.W. thanks the EPSRC for funding via the Centre for Doctoral Training in Plastic Electronics.

\section{Supporting Information Available}

Additional experimental procedures and characterization data such as scanning electron microscopy images, additional atomic force microscopy images, photos illustrating the phase transition to the yellow phase and additional data about the spread of solar cell performance can be found in the Supporting Information. 


\section{References}

(1) Correa-Baena, J.-P.; Abate, A.; Saliba, M.; Tress, W.; Jacobsson, T. J.; Grätzel, M.; Hagfeldt, A. The rapid evolution of highly efficient perovskite solar cells. Energy Environ. Sci. Energy Environ. Sci 2017, 710, 710-727.

(2) Yang, W. S.; Park, B.-W.; Jung, E. H.; Jeon, N. J.; Kim, Y. C.; Lee, D. U.; Shin, S. S.; Seo, J.; Kim, E. K.; Noh, J. H.; Seok, S. I. Iodide management in formamidinium-leadhalide-based perovskite layers for efficient solar cells. Science 2017, 356, 1376-1379.

(3) Momblona, C.; Gil-Escrig, L. N.; Bandiello, E.; Hutter, E. M.; Sessolo, M.; Lederer, K.; Blochwitz-Nimoth, J.; Bolink, H. J. Efficient vacuum deposited p-i-n and n-i-p perovskite solar cells employing doped charge transport layers. Energy Environ. Sci. 2016, 3456, 3456-3463.

(4) Saliba, M.; Matsui, T.; Seo, J.-Y.; Domanski, K.; Correa-Baena, J.-P.; Nazeeruddin, M. K.; Zakeeruddin, S. M.; Tress, W.; Abate, A.; Hagfeldt, A.; et al., Cesiumcontaining triple cation perovskite solar cells: improved stability, reproducibility and high efficiency. Energy Environ. Sci. 2016, 9, 1989-1997.

(5) Koh, T. M.; Fu, K.; Fang, Y.; Chen, S.; Sum, T. C.; Mathews, N.; Mhaisalkar, S. G.; Boix, P. P.; Baikie, T. Formamidinium-containing metal-halide: An alternative material for near-IR absorption perovskite solar cells. J. Phys. Chem. C 2014, 118, 16458-16462.

(6) Eperon, G. E.; Stranks, S. D.; Menelaou, C.; Johnston, M. B.; Herz, L. M.; Snaith, H. J. Formamidinium lead trihalide: a broadly tunable perovskite for efficient planar heterojunction solar cells. Energy Environ. Sci. 2014, 7, 982-988.

(7) Habisreutinger, S. N.; Mcmeekin, D. P.; Snaith, H. J.; Nicholas, R. J. Research Update: Strategies for improving the stability of perovskite solar cells. APL Mater. 2016, 4 , 091503. 
(8) McMeekin, D. P.; Sadoughi, G.; Rehman, W.; Eperon, G. E.; Saliba, M.; Hörantner, M. T.; Haghighirad, A.; Sakai, N.; Korte, L.; Rech, B.; et al., A mixedcation lead mixed-halide perovskite absorber for tandem solar cells. Science 2016, 351, 151-155.

(9) Wang, Z.; McMeekin, D. P.; Sakai, N.; van Reenen, S.; Wojciechowski, K.; Patel, J. B.; Johnston, M. B.; Snaith, H. J. Efficient and air-stable mixed-cation lead mixed-halide perovskite solar cells with n-doped organic electron extraction layers. Adv. Mater. 2017, 29, 1604186.

(10) Lv, S.; Pang, S.; Zhou, Y.; Padture, N. P.; Hu, H.; Wang, L.; Zhou, X.; Zhu, H.; Zhang, L.; Huang, C.; et al., One-step solution-processed formamidinium lead trihalide $\left(\mathrm{FAPbI}_{(3-\mathrm{x})} \mathrm{Cl}_{\mathrm{x}}\right)$ for mesoscopic perovskite-polymer solar cells. Phys. Chem. Chem. Phys. 2014, 16, 19206.

(11) Leyden, M. R.; Jiang, Y.; Qi, Y. Chemical vapor deposition grown formamidinium perovskite solar modules with high steady state power and thermal stability. J. Mater. Chem. A 2016, 4, 13125-13132.

(12) Liu, M.; Johnston, M. B.; Snaith, H. J. Efficient planar heterojunction perovskite solar cells by vapour deposition. Nature 2013, 501, 395-398.

(13) Eperon, G. E.; Leijtens, T.; Bush, K. A.; Prasanna, R.; Green, T.; Wang, J. T.-W.; McMeekin, D. P.; Volonakis, G.; Milot, R. L.; May, R.; et al., Perovskite-perovskite tandem photovoltaics with optimized band gaps. Science (New York, N.Y.) 2016, 354, 861-865.

(14) Zhao, D.; Ke, W.; Grice, C. R.; Cimaroli, A. J.; Tan, X.; Yang, M.; Collins, R. W.; Zhang, H.; Zhu, K.; Yan, Y. Annealing-free efficient vacuum-deposited planar perovskite solar cells with evaporated fullerenes as electron-selective layers. Nano Energy 2016, 19, 88-97. 
(15) Yu, Y.; Wang, C.; Grice, C. R.; Shrestha, N.; Chen, J.; Zhao, D.; Liao, W.; Cimaroli, A. J.; Roland, P. J.; Ellingson, R. J.; et al., Improving the performance of formamidinium and cesium lead triiodide perovskite solar cells using lead thiocyanate additives. ChemSusChem 2016, 9, 3288-3297.

(16) Xie, Z.; Sun, S.; Yan, Y.; Zhang, L.; Hou, R.; Tian, F.; Qin, G. G. Refractive index and extinction coefficient of $\mathrm{NH}_{2} \mathrm{CH}=\mathrm{NH}_{2} \mathrm{PbI}_{3}$ perovskite photovoltaic material. $J$. Phys.: Condens. Matter 2017, 29, 245702.

(17) Stoumpos, C. C.; Malliakas, C. D.; Kanatzidis, M. G. Semiconducting tin and lead iodide perovskites with organic cations: Phase transitions, high mobilities, and nearinfrared photoluminescent properties. Inorg. Chem. 2013, 52, 9019-9038.

(18) Binek, A.; Hanusch, F. C.; Docampo, P.; Bein, T. Stabilization of the trigonal hightemperature phase of formamidinium lead iodide. J. Phys. Chem. Lett. 2015, 6, 12491253.

(19) Patel, J. B.; Wong-Leung, J.; Van Reenen, S.; Sakai, N.; Wang, J. T. W.; Parrott, E. S.; Liu, M.; Snaith, H. J.; Herz, L. M.; Johnston, M. B. Influence of interface morphology on hysteresis in vapor-deposited perovskite solar cells. Adv. Electron. Mater. 2016, 1600470, 1600470.

(20) Wright, A. D.; Verdi, C.; Milot, R. L.; Eperon, G. E.; Pérez-Osorio, M. A.; Snaith, H. J.; Giustino, F.; Johnston, M. B.; Herz, L. M. Electron-phonon coupling in hybrid lead halide perovskites. Nat. Commun. 2016, 7, 11755.

(21) Wright, A. D.; Milot, R. L.; Eperon, G. E.; Snaith, H. J.; Johnston, M. B.; Herz, L. M. Band-Tail Recombination in Hybrid Lead Iodide Perovskite. ADVANCED FUNCTIONAL MATERIALS 2017, 27.

(22) de Quilettes, D. W.; Vorpahl, S. M.; Stranks, S. D.; Nagaoka, H.; Eperon, G. E.; 
Ziffer, M. E.; Snaith, H. J.; Ginger, D. S. Impact of microstructure on local carrier lifetime in perovskite solar cells. Science 2015, 348, 683-686.

(23) Pellet, N.; Gao, P.; Gregori, G.; Yang, T.-Y.; Nazeeruddin, M. K.; Maier, J.; Grätzel, M. Mixed-organic-cation perovskite photovoltaics for enhanced solar-light harvesting. Angew. Chem., Int. Ed. Engl. 2014, 53, 3151-7.

(24) Rehman, W.; Milot, R. L.; Eperon, G. E.; Wehrenfennig, C.; Boland, J. L.; Snaith, H. J.; Johnston, M. B.; Herz, L. M. Charge-carrier dynamics and mobilities in formamidinium lead mixed-halide perovskites. Adv. Mater. 2015, 27, 7938-7944.

(25) Patel, J. B.; Milot, R. L.; Wright, A. D.; Herz, L. M.; Johnston, M. B. Formation dynamics of $\mathrm{CH}_{3} \mathrm{NH}_{3} \mathrm{PbI}_{3}$ perovskite following two-step layer deposition. J. Phys. Chem . Lett. 2016, 7, 96-102.

(26) Crothers, T. W.; Milot, R. L.; Patel, J. B.; Parrott, E. S.; Schlipf, J.; MüllerBuschbaum, P.; Johnston, M. B.; Herz, L. M. Photon reabsorption masks intrinsic bimolecular charge-carrier recombination in $\mathrm{CH}_{3} \mathrm{NH}_{3} \mathrm{PbI}_{3}$ perovskite. Nano Letters $\mathbf{2 0 1 7}$, 17, 5782-5789, PMID: 28792767.

(27) Johnston, M. B.; Herz, L. M. Hybrid perovskites for photovoltaics: Charge-carrier recombination, diffusion, and radiative efficiencies. Acc. Chem. Res. 2016, 49, 146154.

(28) Sessolo, M.; Momblona, C.; Gil-Escrig, L.; Bolink, H. J. Photovoltaic devices employing vacuum-deposited perovskite layers. MRS Bulletin 2015, 40, 660-666. 


\section{Graphical TOC Entry}

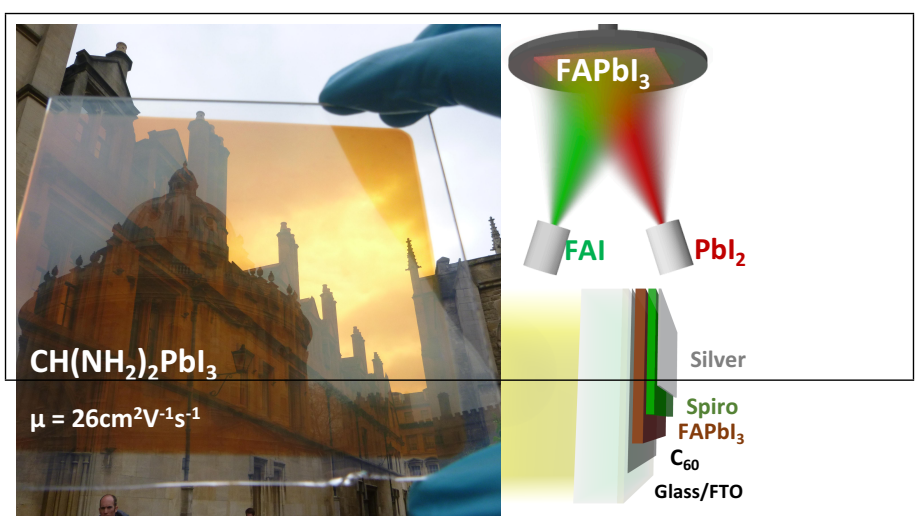

